\begin{tabular}{|c|c|c|}
\hline & International Journal of Engineering \& Technology, $7(4.27)(2018) 115-120$ & \\
\hline & International Journal of Engineering \& Technology & \\
\hline & Website: www.sciencepubco.com/index.php/IJET & \\
\hline SPC & Research paper & \\
\hline
\end{tabular}

\title{
A Study on the Effect of Intelligent Speed Adaptation (ISA) by Using Human Speech and the Acceptance
}

\author{
Ahmad Khushairy Makhtar ${ }^{1 *}$ Ahmed Khameini ${ }^{2}$ \\ ${ }^{12}$ Faculty of Mechanical Engineering, Universiti Teknologi MARA \\ *Corresponding author E-mail: ahmadkhushairy@salam.uitm.edu.my
}

\begin{abstract}
Intelligent Speed Adaptation (ISA) is an in-vehicle system that support drivers compliance with the speed limit. ISA is in fact a collective term for various different systems. Today, speeding was listed as the major cause of road accidents and traffic fatalities worldwide. By having a reliable and acceptable system that could alert the drivers about the speed limit in any particular areas, it will help in reducing the number of road accidents worldwide. This study was conducted to develop a system of Intelligent Speed Adaptation (ISA) by using GPS that would alert the bus drivers in UiTM Shah Alam about speed limits in any particular areas and it must be reliable and acceptable. This research is to determine the factors of acceptance from the drivers towards the ISA system. The system developed was an advisory system. Hence, the way this system give warning about the speed limit to the driver is an important criterion to be taken care of. The output parameter of for this study is the driver's acceptance towards this ISA system and they must be happy to have this system inside their vehicles.
\end{abstract}

Keywords: Intelligent Speed Adaptation, Road Safety, Driver's Acceptance, Bus Drivers

\section{Introduction}

The speeding problem has led to the occurrence of road accidents. The increasing of the velocity of a vehicle could be used to describe the speeding matter. This problem caused the fatal accident which must be avoided especially in a university compound, because there are not only the students and lecturers using the road, but the workers, parents and pedestrians used the same road too. The current intervention to control speeding problem in our campus is via speed hump. A speed hump is a speed reducing feature of road design to slow traffic down via a vertical deflection. A speed hump is a rounded traffic calming device used to reduce vehicle speed and volume on the road. Humps are placed across the road and are often installed in a series of several humps to prevent cars from speeding before and after the hump. Common speed hump shapes are parabolic, circular and sinusoidal. This intervention was used in a long time ago and proven to help in reducing speed problem.

However, the effect of the speed hump was limited to a specific location and time. They may be able to reduce speed but inappropriate for a larger scale implementation. In conjunction to overcome these limitations, utilisation of technology such as Intelligent Speed Adaptation (ISA) is another option to reduce the speeding problem among users in a wide range of period and location as long as the system does not turn off by the driver. Intelligent Speed Adaptation (ISA) is a system that continually monitors about vehicle speed and the local speed limit on a road and will implement an action such as giving a warning or discourages the drivers when the vehicle is detected to be exceeding the speed limit. This action can be done through an advisory system, where the driver is warned, or through an intervention system where the driving systems of the vehicle automatically control the system to decrease the speed of the vehicle.
An ISA system will consist of a GPS receiver in the car to determine the position of the car on a road network information. The speed limit information of every road section is added to the road network information. So, the in-car system knows its position on the road network and the prevailing speed limit. The driver will receive feedback about impending speeding. Many other countries are taking into consideration the implementation of the ISA system by conducting studies and testing to recognise its usefulness to solve the speeding problem. Therefore, it is essential to develop a convenient and reliable system of ISA with the help of GPS functionalities.

The objective of this research is to study the effect of Intelligent Speed Adaptation (ISA) system with human speech sound among bus drivers in UiTM Shah Alam and determine the factors of acceptance of the drivers towards the ISA system.

\section{Literature Review}

ISA is a kind of speed limiter. The only difference is the system did not set the correct speed limit automatically. The drivers need to set the speed limit by themselves. The research on ISA has been continued in Sweden after about ten year's gaps. From the numbers of projects in Sweden, it has culminated in the larger scale of research from 1999 to 2001. About 5000 vehicles with an ISA system were moving on the Swedish roads. Most of these vehicles were installed with an advisory or warning type of ISA, but a few hundred used an intervening system, being fitted with the haptic throttle, whereby the accelerator pedal became stiffer when the speed limit was exceeded.[1] The national ministry has funded the second major project in the Netherlands. It was conducted from 1999 to 2000. This project was the field trial with 20-equipped vehicles in a small section of the Dutch city of Tilburg, which was conducted on behalf of the Dutch Ministry of Transport. The driv- 
ers were residents of an area called Campenhoef, who drove with an ISA car for a total of two months of which the first two weeks were with the ISA system off. Speed limits of $30 \mathrm{~km} / \mathrm{h}$ were enacted within Campenhoef. The ISA system also operated on 50 $\mathrm{km} / \mathrm{h}$ roads surrounding Campenhoef and on two $80 \mathrm{~km} / \mathrm{h}$ rural roads. The experiment used a group of identical cars, each fitted with a simple digital road map and a non-overridable ISA, which used fuel restriction to limit speed. The position was obtained from GPS. The cars were each used by six subjects so that there were 120 participants in total. An ISA bus also was tested.[2] Since 2000, the pace and geographic spread of research on ISA have increased. In the United Kingdom, the ISA project began in 2000. This project was focused on the behaviours of the drivers when using an ISA-equipped vehicle for their everyday driving. The project consists of four different field trials with 20 different vehicles. Each trial would last for six months. From Sweden, United Kingdom (UK) and the Netherlands, the study regarding ISA system has started to expand in other countries as well. As an example, two projects were conducted in Belgium from 2001 to 2002. The first project was carried out in the City of Ghent. The purpose of this project was to investigate the capability of ISA assisting the community in its road safety strategy. The ISA system would be a new future of traffic calming in that region. The second project was focused mainly on a technical demonstration of a capability to deliver dynamic ISA as one of a range of invehicle telematics services. Moreover, the knowledge about ISA concept has widened around the world within the last few years. In the Asia region, Australia was the first country to have a project on the ISA system. The most recognised vehicle-based safety project in Australia is the TAC Safe Car project.[3] This project has included the function of ISA as well to be tested. Japan has followed Australia's move by funding a project named Soft Car. Before this, Japanese has applied a concept of indication speeding to other drivers using lights in a vehicle's rear window. After this project was introduced, they have changed it to a better way which was an ISA system [1]. In Malaysia, not much study has been done regarding ISA. Some were focusing on the using of ISA in personal vehicle itself, none has been focusing on commercial vehicle such as buses or truck. [4], [5] This study is focusing on the usage of ISA on Bus drivers and it effectiveness.

\section{Methodology}

The driver's speed management pattern was determined by an initial survey. From the survey, we could also determine the level of driver's knowledge about Intelligent Speed Adaptation (ISA). ISA is one of the tools that we could use to enhance the speed management of the drivers. Besides, we also could determine the most preferred way of the system give a warning to the drivers from this survey.

\subsection{Experiment}

An experiment would be conducted by implementing this system in the vehicles of the 20 respondents. The respondents were among the bus drivers in UiTM Shah Alam, and the data will be collected along their journey within UiTM Shah Alam's compound. GPS was a device being used to track the speed profile of the respondents. The data would be collected in this experiment are the speed profile, the speed variation of before and during using the system and the level of acceptance of the respondents towards the system. The data collected was used to prove the initial survey whether it is right or not.

\subsection{Survey}

A final survey would be conducted to analyze the respondent's opinion about this system development. Any suggestion about how we could enhance the efficiency of this system is most welcome. We also would like to know about the importance of this system in our vehicles and is it helpful in improving our speed management then reducing the traffic fatalities in Malaysia.

\subsection{UiTM Routes}

This study was conducted within UiTM Shah Alam's compound. Therefore, the UiTM Shah Alam routes for bus drivers were used for this experiment to complete this study. The starting point of the journey was at the bus stop Dataran Cendekia. After that, the bus drivers would finish their one loop of the journey at the same point too. Along the route, it was divided into 5 zones to achieve the accuracy of this study. The figure below shows the UiTM Shah Alam's route.

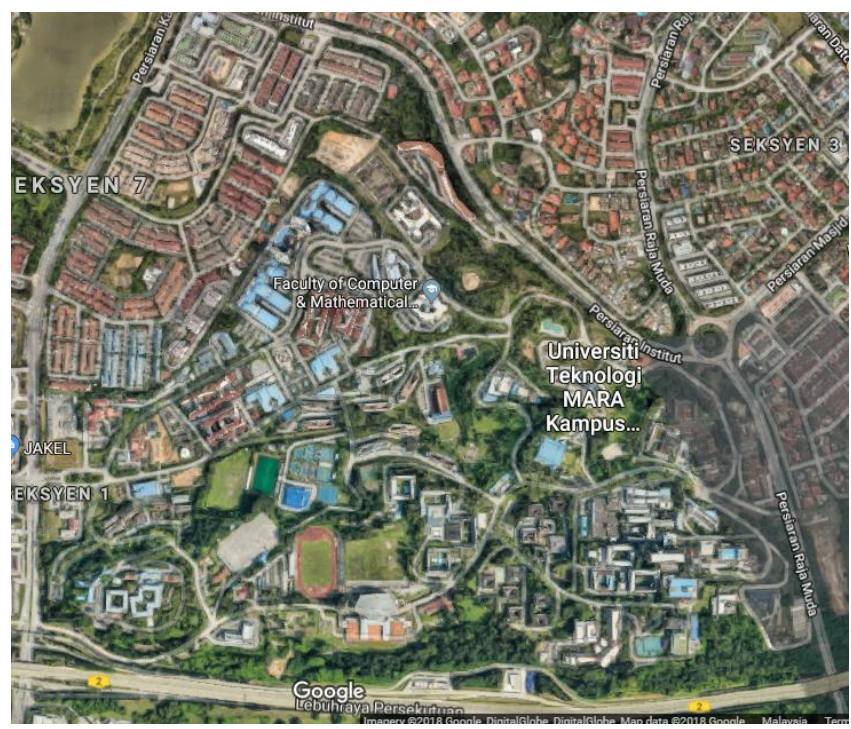

Fig1: The UiTM Shah Alam's Route

The highlighted road was represented by their respective zone. Each zone has its own criteria so that we could know how the bus drivers would get response to the ISA system in every zones. The Table 1 shows the details of each zone.

Table 1: Details of each zones

\begin{tabular}{|c|c|c|}
\hline Zones & Coordinates & $\begin{array}{l}\text { Length } \\
\text { (m) }\end{array}$ \\
\hline Zone 1 & $\begin{array}{l}\text { From N3 }{ }^{\circ} 04.170^{\prime} \mathrm{E} 101^{\circ} 29.690^{\circ} \text { to } \mathrm{N}^{\circ} \\
04.085^{\prime} \mathrm{E} 101^{\circ} 29.589^{\prime}\end{array}$ & 288 \\
\hline Zone 2 & $\begin{array}{l}\text { From N3 }{ }^{\circ} 04.002^{\prime} \mathrm{E} 101^{\circ} 29.560^{\prime} \text { to } \mathrm{N} 3^{\circ} \\
03.973^{\prime} \mathrm{E} 101^{\circ} 29.662^{\prime}\end{array}$ & 234 \\
\hline Zone 3 & $\begin{array}{l}\text { From } \mathrm{N} 3^{\circ} 03.910^{\prime} \mathrm{E} 101^{\circ} 29.703^{\circ} \text { to } \mathrm{N}^{\circ} \\
03.864^{\prime} \mathrm{E} 101^{\circ} 29.736^{\prime}\end{array}$ & 347 \\
\hline Zone 4 & $\begin{array}{l}\text { From } \mathrm{N} 3^{\circ} 04.246^{\prime} \mathrm{E} 101^{\circ} 30.222^{\prime} \text { to } \mathrm{N}^{\circ} \\
04.269^{\prime} \mathrm{E} 101^{\circ} 30.079^{\prime}\end{array}$ & 413 \\
\hline Zone 5 & $\begin{array}{l}\text { From N3 }{ }^{\circ} 04.362^{\prime} \mathrm{E} 101^{\circ} 29.922^{\prime} \text { to } \mathrm{N} 3^{\circ} \\
04.351^{\prime} \mathrm{E} 101^{\circ} 29.848^{\prime}\end{array}$ & 481 \\
\hline
\end{tabular}

\subsection{Zones Description}

\section{Zone 1}

Zone 1 was a 288 meters long. The type of road within this zone was straight and flat. Usually, people will speed up their vehicles on this kind of road. Therefore, it was essential to consider the effect of the ISA system on the bus drivers within this zone.

\section{Zone 2}

Zone 2 was a 234 meters zone. The type of road within this zone was climbing the hill and hard turn. People tend to go a bit faster to help them climb the hill successfully. However, some people chose to slow down and use the lower gear to help them doing so. 
Therefore, it was essential to find out how an ISA system would effect to different bus drivers.

\section{Zone 3}

Zone 3 was a 347 meters zone. The type of road within this zone was down the hill and took a left turn on the junction three. Some people enjoy driving down the hill since it could be faster but some people chose to be careful so any accident would not happen. Therefore, it was essential to know the effect of ISA on this kind of road.

\section{Zone 4}

Zone 4 was a 413 meters zone. The type of road within this zone was climbing uphill. People take different action in this situation. Therefore, it was important to know what the bus drivers would take action and is ISA help to improve their speed management.

\section{Zone 5}

Zone 5 was a 481 meters zone. The type of road within this zone is down the hill, and hard turn left. Most people love to drive faster on this kind of road. Therefore, it is essential to study the help of ISA system on this kind of road.

\subsection{Road's Characteristics}

Based on five zones that we identified, there were three types of road can be considered for further analysis.

\section{Straight Road}

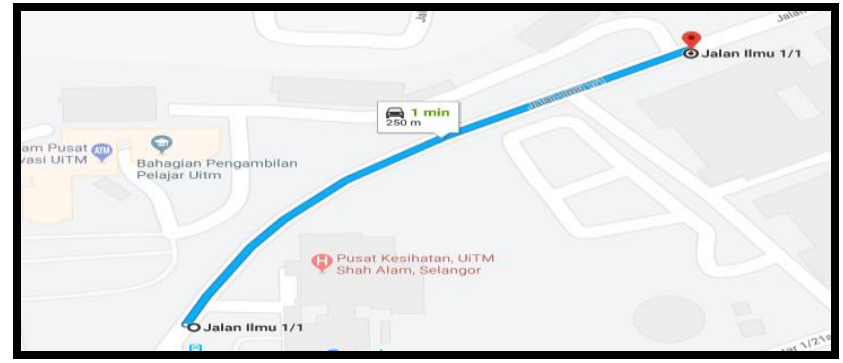

Fig 2: Zone 1

Fig 2 was the only zone with the straight and flat type of road. The length of this zone is 288 meters. From the experiment, we have collected the data about the speed variation of the respondents within this zone. We have compared the speed of the respondents between before implementation of ISA system and during the implementation of ISA system. This ISA system was used to study about the effect of alert sound (human speech) to the speed profile of the respondents and their acceptance towards this kind of speed assistant system. From 20 respondents who involved in this experiment, we have calculated the overall average speed for before implementation of ISA system and during the implementation of ISA system.

\section{Sloppy Road}

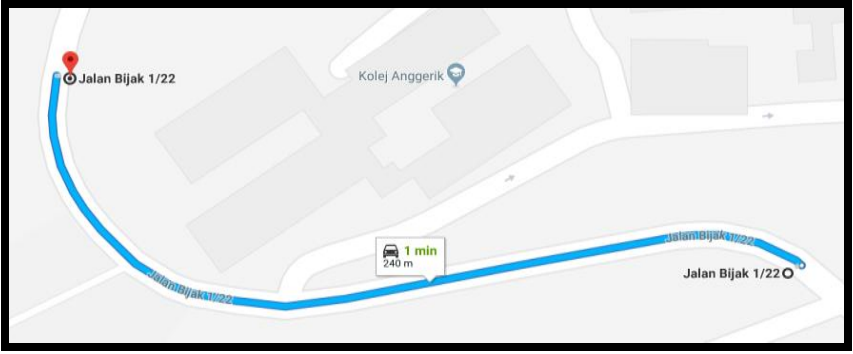

Fig 3: Zone 2

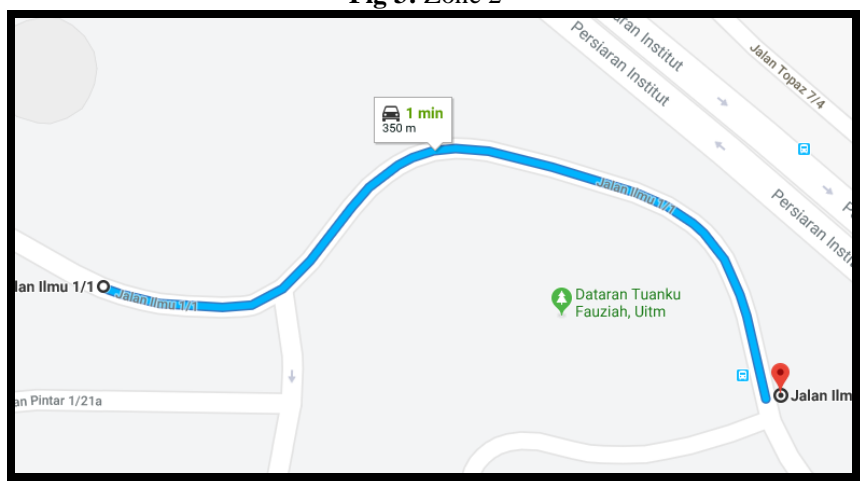

Fig 4: Zone 4

Fig. 5 and Fig. 6 shows the route were covered from sloppy road. Zone 2 and Zone 4 were the zones with the sloppy road. Firstly, Zone 2 was the zone with the length of 234 meters. From this experiment, we have collected the data about the speed variation of the respondents within this zone.

Next, Zone 4 was a zone with the length of 413 meters. It also has the same road's characteristic as the Zone 2. From the experiment, we could know whether the ISA system with the human speech kind of alert sound would help the respondents to obey the imposed speed limits or not.

Lastly, after we have analyzed the data from Zone 2 and Zone 4 who shared the same road's characteristic, we could see that the speed reduction occurred on this kind of road was the least compared to the others.

\section{Cornering Road}

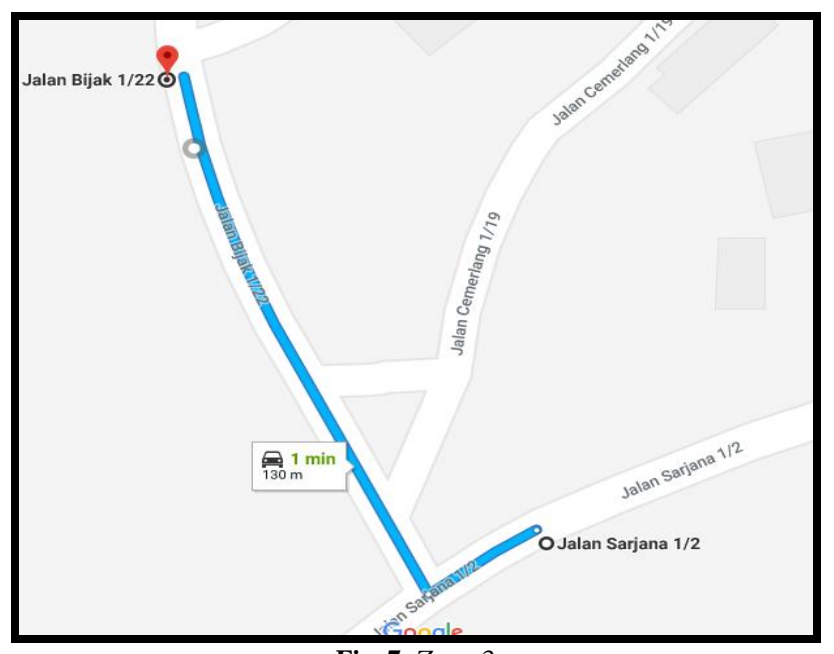

Fig. 7: Zone 3

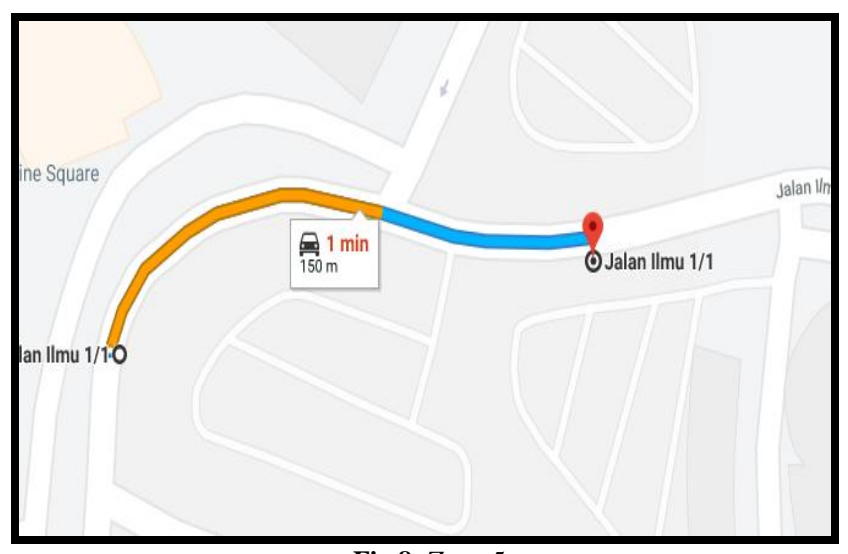

Fig 8: Zone 5 
As shown in Fig. 7 and Fig 8, the main characteristic of the road in Zone 3 and Zone 5 is a corner. The respondents need to take on hard left turn in both zones. However, the condition of the corner in Zone 3 was on the junction three. The length of this zone is 347 meters. From the experiment, we have collected the data about the speed variation of the respondents between before implementation of ISA system and during the implementation of ISA system. The experiment was to test about the effect of the human speech kind of alert sound in the ISA system towards the speed management of the respondents who had involved in this experiment.

Furthermore, Zone 5 was a little bit different compared to Zone 3 . The difference was in term of the corner's condition. The corner in Zone 5 was an immediate left turn. This situation will allow the respondents to move faster than in Zone 3. The length of this zone is 481 meters.

\section{Results and Discussions}

\subsection{Overall Average Speed before and During Imple- mentation of ISA}

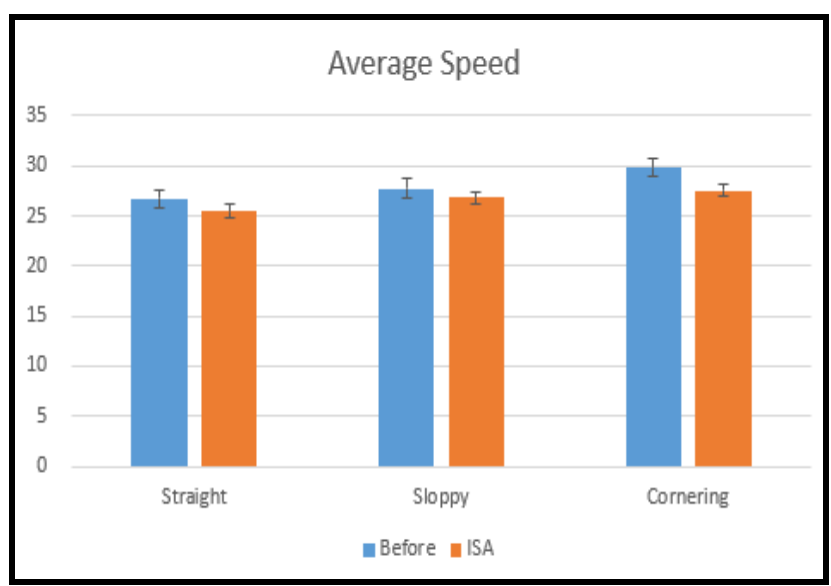

Fig 9: The overall average speed based on the road's characteristic.

From the Fig 9 above, it shows the difference happened on different road's characteristic. We have three different roads from the 5 zones which are a straight, sloppy and cornering road. The lowest speed reduction has occurred on the sloppy road which is 0.93 $\mathrm{km} / \mathrm{h}$. A paired-samples t-test was conducted to compare the average speed of the bus before and during implementation of ISA. There was a significant difference in the speed for Sloppy Road before $(M=26.77, S D=2.11)$ and During the implementation of ISA $(\mathrm{M}=25.49, \mathrm{SD}=2.16), \mathrm{t}(39)=4.462, \mathrm{p}<0.001$.

This is because the bus drivers need to drive their bus climbing a hill successfully and thus requires more power compared to another road condition. Therefore, the bus drivers might choose to ignore the ISA alert sound when they have exceeded the speed limit on this zone so that they could climb the hill successfully.

Next, the highest speed reduction has occurred on the cornering road. The zones with this road's characteristic were Zone 3 and Zone 5 . The speed reduction was $2.25 \mathrm{~km} / \mathrm{h}$. A paired-samples ttest was conducted to compare the average speed of the bus before and during implementation of ISA. There was a significant difference in the speed for Sloppy Road before $(\mathrm{M}=27.78 \mathrm{SD}=1.03)$ and During the implementation of ISA $(\mathrm{M}=26.85, \mathrm{SD}=1.23)$, $\mathrm{t}(39)=7.844, \mathrm{p}<0.001$. It shows that the bus drivers were able to use the ISA system on this kind of road very well.

Lastly, the speed reduction occurred on the straight road was 1.28 $\mathrm{km} / \mathrm{h}$. Zone 1 was the only zone with this characteristic. The difference was insignificant based on the statistical analysis, before $(\mathrm{M}=29.82, \mathrm{SD}=2.84)$ and During the implementation of ISA $(\mathrm{M}=27.57, \mathrm{SD}=2.48), \mathrm{t}(19)=1.927, \mathrm{p}=0.069$. The speed reduction occurred was in the middle between the sloppy road and cornering road. This is because the bus drivers tend to ignore the alert sound from the ISA system on this road. However, some drivers with a great personality and discipline would pay attention to their driving speed and be responsible for slowing down if they have exceeded the limit. ISA will fit these drivers very well.

\subsection{Questionnaire: Factors of Acceptance of the Bus Drivers towards an ISA System}

\subsubsection{Do you ever Heard about Intelligent Speed Adaptation} (ISA) System?

\section{Do you ever heard about Intelligent Speed Adaptation (ISA) system?}

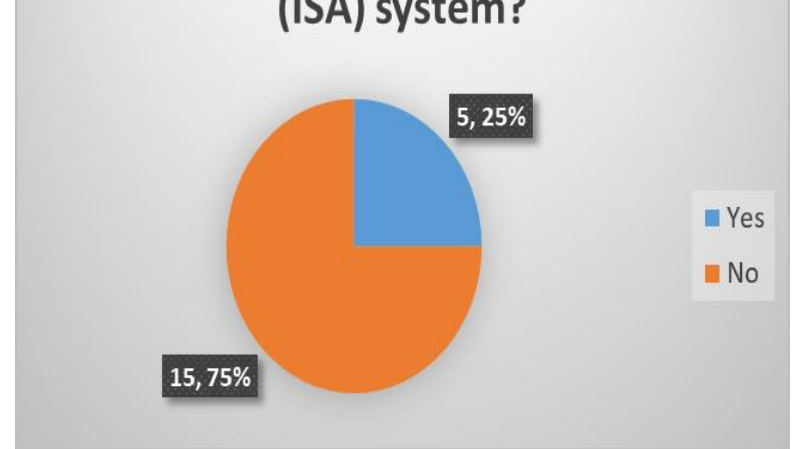

Fig 10: The knowledge about Intelligent Speed Adaptation (ISA) system.

From the Fig 10, we should know that most of the respondents did not know about the Intelligent Speed Adaptation (ISA) system. This situation happened because of the lack of exposure of the bus drivers towards the new speed management technology like this. The loose enforcement from the responsible authorities also has led to this matter as well. Therefore, there is a need for the responsible authorities or employers to enforce the usage of this kind of ISA system. They could distribute brochures or organize a course about the benefit of using this ISA system for all drivers. Hence, it will increase the awareness of the drivers about the good speed management while driving on the road.

\subsubsection{Do you feel Any Stress while using this ISA system?}

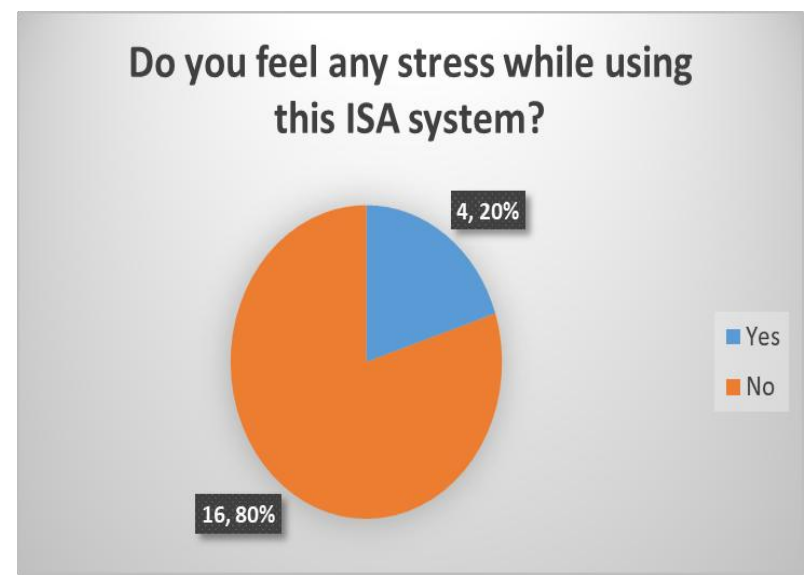

Fig 11: Respondents’' stress level.

The Fig 11 shows that 16 out of 20 respondents did not feel any stress while using this ISA system. There are two reasons why they did not feel any stress while using this system. Firstly, they must be a person who will obey the imposed speed limits. When they want to follow the right speed limits, this system will help them, and it could be a pleasure instead of pressure. Secondly, they might be comfortable with the system. When the human speech sounded, it will not annoy the bus drivers. Therefore, the 
bus drivers will pay attention and reduce their speed to the allowable speed.

However, 4 of them felt some stress while using this ISA system. There are two reasons why they felt that way. Firstly, the bus drivers were not comfortable with this system. The sound of the human speech might interrupt the concentration of the bus drivers. Secondly, they were hard to change their driving style. In this matter, the bus drivers will only slow down when they cannot move faster such as obstacles ahead, road bumps or congested traffic situation.

\subsubsection{What is your Action when the ISA Device was sounding?}

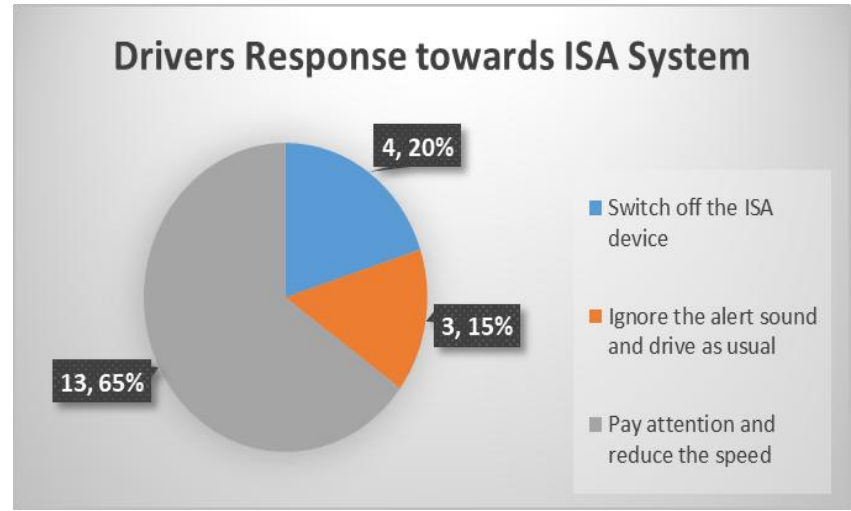

Fig 12: The driver's response towards the ISA system.

Fig 12 above shows the response of the bus drivers towards the ISA system. About 13 respondents which represent $65 \%$ of them chose to pay attention and reduce their current speed. It shows that this kind of ISA system has helped them to have better speed management and obey the law. Therefore, the road will be safer for everyone. Within UiTM Shah Alam's compound, we would have car drivers, motorcycle riders and pedestrians as well. The better speed management of the bus drivers within UiTM Shah Alam's compound will benefit all of them too.

However, there were four respondents who chose to switch off the ISA device and three respondents who chose to ignore the sound and drive as usual. From our point of view, the four respondents who chose to switch off the ISA device was not comfortable to have any device instructing them while driving. They might lose their focus on what is ahead while paying attention to the device. Furthermore, the three respondents who chose to ignore the alert sound might think that as long they could reach the destinations, then it is safe. This kind of drivers needs a strong enforcement of the law to make them obey it.

4.2.4 How do you feel when the ISA Device was sounding while you are driving?

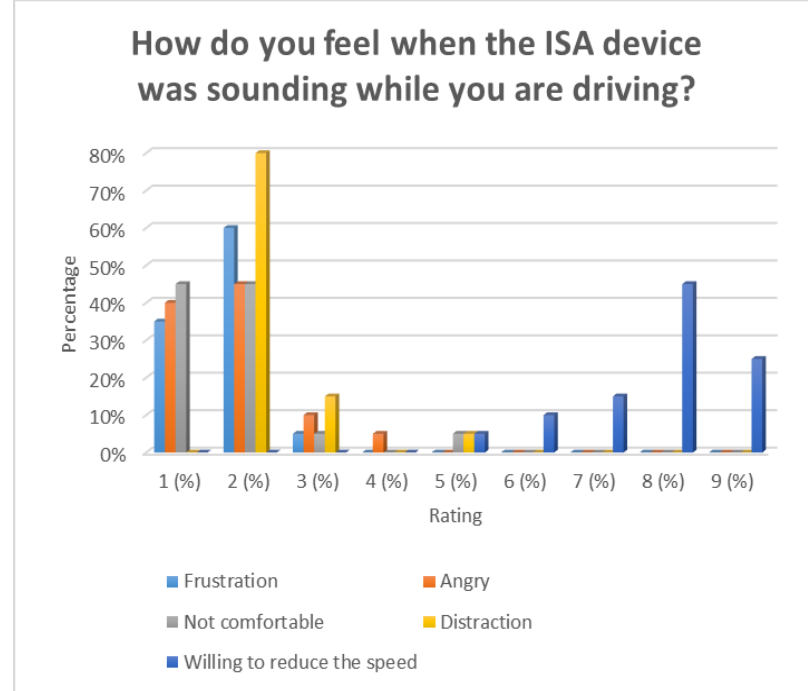

Fig 13: Respondents' feeling when the ISA device was sounding.

Fig 13 above showed the feeling of the respondents when the ISA device was sounding while they were driving. The rating was from the lowest which is " 1 " and the highest which is "9". The rate from " 1 " to " 3 " could be considered as low and shows that the respondents disagreed with the statements. The rate from "4" to " 6 " could be considered as medium and shows that the respondents agreed to the statements conditionally. The rate from "7" to "9" could be considered as high and shows that the respondents agreed with the statements unconditionally.

From the Figure 4.3.6, we could conclude that most of them did not get frustrated, uncomfortable, and angry and looked it as a distraction for them. While a small group of the respondents were felt angry and look at it as a distraction in a certain condition. However, there were few respondents chose to reduce their speed in certain condition as well. Lastly, several respondents were agreed to reduce their speed when the ISA device was sounding while they were driving. Hence, it shows that the respondents were willing to accept this kind of ISA system and did not find it as a distraction or interruption towards them.

4.2.5 What Type of Alert sound do you Prefer the Most for an ISA System?

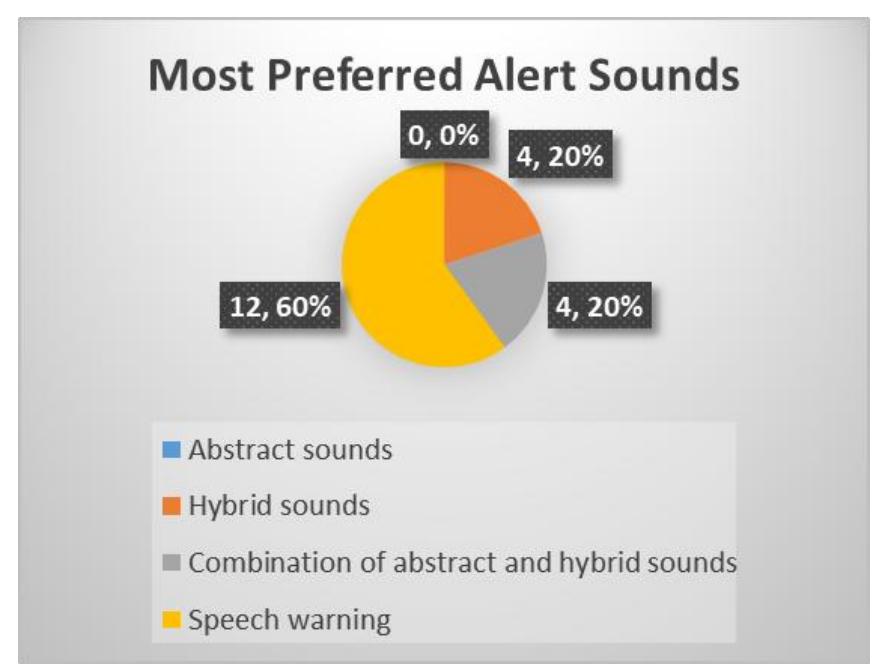

Fig 14: The most preferred alert sound.

Fig 14 above shows the most preferred alert sound from the respondents. About $60 \%$ of the respondents preferred speech warning or known as human speech kind of alert sound. Since the ISA system used in this experiment is the one with the speech warning alert sound, so they have already known how it would work for them. We also could know that they were among the respondents 
who are willing to reduce their speed when the ISA device was sounding.

However, there are $20 \%$ of respondents who preferred the hybrid sounds to warn them about the speed limits. Besides, another $20 \%$ of respondents preferred the combination of abstract and hybrid sounds to warn them about the same matter. Therefore, this groups of respondents were among who looks at this kind of ISA system as a distraction and interruption for the drivers.

\section{Conclusion}

The objectives of this study were to study about the effect of ISA system with human speech kind of alert sound towards the speed profile of the UiTM Shah Alam's bus drivers. Besides that, we also want to determine the level of acceptance of the bus drivers towards this kind of ISA system. To observe the effect of the tested ISA system, we have compared the speed profile of the respondents for before implementation of ISA system and during the implementation of ISA system. Moreover, to recognize the level of acceptance of the respondents towards this kind of ISA system, we have distributed a set of the questionnaire consisted eight different questions to every respondent. From what we have obtained in this study, they are several conclusions could be made.

Firstly, we have calculated the overall average speed for before implementation of ISA system (human speech) and during the implementation of ISA system. From the calculated data, we could differentiate the speed profile of the respondents between both situations. Therefore, we have concluded that the speed profile of 20 respondents has decreased during the implementation of ISA system. Zone 5 has recorded the highest speed reduction between before implementation of ISA system and during the implementation of ISA system. It shows that the usage of this ISA system (human speech) has helped the respondents at most when passed by this zone. However, the developed error bars on the overall average speed of the respondents for both situations in Zone 1 shows that they have the least significant difference within that zone. So, it could be concluded that another road safety measure can be implemented in this zone and measure its significant difference. Besides that, the comparison of overall average speed before and during the implementation of ISA on different road's characteristic shown that the usage of ISA system with human speech kind of alert sound was effective at most on the cornering road.

Next, the answers on the distributed questionnaires have been analyzed to observe the level of acceptance of the respondents towards this ISA system (human speech). From the data gained by the questionnaires, it shows that most of the respondents did not think that the ISA system as a distraction or interruption for them while driving. Besides, the respondents also willing to reduce their speed when the ISA device was sounding while they were driving. The willingness of the respondents to reduce their speed shows that the level of acceptance of the respondents towards this ISA system (human speech) is high. Moreover, $65 \%$ of the respondents have preferred the usage of human speech kind of alert sound in an ISA system. Lastly, the level of acceptance of this ISA system should be study from time to time with different respondents and vehicles.

\section{Acknowledgement}

The author and study team would like to acknowledge the Faculty of Mechanical Engineering, Universiti Teknologi MARA (UiTM) for funding this study
[1] C. A. Kahn (2014) "Investigation of the Use and feasibility of speed warning systems," Ann. Emerg. Med., vol. 64, no. 6, pp. 673674.

[2] G. Saint Pierre and J. Ehrlich (2008). "Impact of Intelligent Speed Adaptation Systems on Fuel Consumption and Driver Behaviour," ITS World Congr.

[3] K. L. Young, M. A. Regan, T. J. Triggs, N. Tomasevic, K. Stephan, and E. Mitsopoulos, (2007) "Impact on car driving performance of a following distance warning system: Findings from the Australian transport accident commission SafeCar project," J. Intell. Transp. Syst. Technol. Planning, Oper.

[4] A. Azad and A. B. Rashid (2011) "Utilization of In-Vehicle Technology for Managing Speed: Challenges and Progress of Intelligent Speed Adaptation (ISA) Pilot Study in Malaysia," vol. 8 , pp. $1-15$.

[5] S. M. R. Ghadiri, J. Prasetijo, A. F. Sadullah, M. Hoseinpour, and S Sahranavard (2013) "Intelligent speed adaptation: Preliminary results of on-road study in Penang, Malaysia," IATSS Res., vol. 36, no. 2 , pp. 106-114,.

\section{References}

